\title{
Income and recurrent events after a coronary event in women
}

\author{
Krisztina D. László · Imre Janszky • \\ Staffan Ahnve
}

Received: 18 October 2007/ Accepted: 15 August 2008/Published online: 18 September 2008

(C) The Author(s) 2008. This article is published with open access at Springerlink.com

\begin{abstract}
Strong evidence supports the existence of a social gradient in poor prognosis in patients with coronary heart disease (CHD). However, knowledge regarding what factors may explain this relationship is limited. We aimed to analyze in women CHD patients the association between personal income and recurrent events and to determine whether lifestyle, biological and psychosocial factors contribute to the explanation of this relationship. Altogether 188 women hospitalized for a cardiac event were assessed for personal income, demographic factors, lipids, inflammatory markers, cortisol, creatinine, lifestyle and psychosocial factors, i.e. alcohol consumption, smoking habits, body-mass index, depressive symptoms, anxiety, vital exhaustion, availability of social interaction, hostility and anger-related characteristics and were followed for cardiovascular death and recurrent acute myocardial infarction (AMI). During the 6-year follow-up 18 patients deceased and 31 experienced cardiovascular death or nonfatal AMI. After adjustment for confounders, patients with medium and high income had lower risk for recurrent events relative to those with low income (HR (95\% CI): $0.38(0.15-0.97)$ and $0.39(0.17-0.93)$, respectively). Controlling for smoking reduced by $12.8 \%$ the risk for recurrent
\end{abstract}

K. D. László · I. Janszky · S. Ahnve ( $₫)$

Preventive Medicine, Department of Public Health Sciences,

Karolinska University Hospital, Norrbacka 6th floor,

Stockholm 17176, Sweden

e-mail: staffan.ahnve@ki.se

K. D. László · I. Janszky

Institute of Behavioural Sciences, Semmelweis University,

Budapest, Hungary events associated with high versus low income, while adjusting for depression decreased the risk for middle versus low income by $13.5 \%$. Anger symptoms explained $16.7 \%$ of the risk for recurrent events associated with middle versus low income and $10.2 \%$ of the risk for high versus low income. We suggest that in women with CHD low income is associated with recurrent events and that smoking, depressive symptomatology and anger symptoms may contribute to the explanation of this relationship.

Keywords Coronary heart disease - Income . Recurrent events · Socioeconomic status · Women

$\begin{array}{ll}\text { Abbreviations } & \\ \text { ACE inhibitor } & \text { Angiotensin-converting enzyme inhibitor } \\ \text { ANOVA } & \text { Analysis of variance } \\ \text { AMI } & \text { Acute myocardial infarction } \\ \text { ApoA1 } & \text { Apolipoprotein A1 } \\ \text { ApoB } & \text { Apolipoprotein B } \\ \text { BDI } & \text { Beck Depression Inventory } \\ \text { BMI } & \text { Body mass-index } \\ \text { CABG } & \text { Coronary artery bypass grafting } \\ \text { CHD } & \text { Coronary heart disease } \\ \text { CI } & \text { Confidence interval } \\ \text { HDL } & \text { High density lipoprotein } \\ \text { HR } & \text { Hazard ratio } \\ \text { hSCRP } & \text { High-sensitivity C-reactive protein } \\ \text { IL-6 } & \text { Interleukin 6 } \\ \text { LP (a) } & \text { Lipoprotein (a) } \\ \text { LDL } & \text { Low density lipoprotein } \\ \text { PCI } & \text { Percutaneous coronary intervention } \\ \text { SD } & \text { Standard deviation } \\ \text { SEK } & \text { Swedish crown } \\ \text { SES } & \text { Socioeconomic status }\end{array}$




\section{Introduction}

Socioeconomic status (SES), defined most often by means of income, educational attainment, occupational class, or a combination of these factors, has been repeatedly found in Western societies to be inversely associated with coronary heart disease (CHD) incidence [1-5], prevalence [6, 7] and mortality $[6,8,9]$. There is evidence for a similar social gradient in morbidity and mortality among patients with an already developed CHD. Patients lower in the socioeconomic hierarchy have worse prognosis and are at higher risk for mortality compared to those in a better socioeconomic position [4, 10-12].

Although the mechanisms that may explain the social gradient in CHD are not entirely understood, it has been suggested that several biological, behavioural and psychosocial risk factors may mediate the association between SES and CHD [13, 14]. Compelling evidence suggests that, compared to those with a better position, individuals from lower socioeconomic groups are more likely to be obese $[3,7,9,15-17]$, smokers $[3,7,9,15-18]$ and heavy drinkers $[3,16]$, to do less physical exercise $[7,9,16]$ and to consume more atherogenic food [15].

Biological risk factors for CHD, such as lipids [3, 15$18]$, inflammatory markers $[19,20]$, haemostatic factors [21, 22], blood pressure [23], glucose levels [16, 17], heart rate [3], history of diabetes [17, 18] and lower cortisol response to stress [24] have also been shown to be related to socioeconomic measures.

At the same time, those in lower socioeconomic position seem to score higher on psychological questionnaires measuring depression [5, 25], anxiety [5], vital exhaustion [24], stress [26], work-related stressors [16], hostility [27], anger [16], while they report lower levels of social support $[16,24,26]$.

Due to their relation to socioeconomic measures, on the one hand, and to CHD on the other, the above factors may be regarded as potential mediators of the relationship between socioeconomic position and disease. However, despite this theoretical background, only a limited number of studies have investigated whether these risk factors really contribute to the explanation of the socioeconomic differences in cardiovascular morbidity and mortality in initially healthy samples $[1,6-8,28-30]$ or in CHD patients.

Except for the SESAMI Study [10] and the Beta Blocker Heart Attack Trial [31] we know of no other studies that have examined biological, lifestyle-related or psychosocial factors as potential explanatory factors of the socioeconomic differential in prognosis in CHD. These two studies were, however, conducted on either mixed or male samples, therefore paid less or no attention to women patients. Women's socioeconomic position [32], cardiovascular risk factors [33], the pattern of the development and prognosis of CHD [33, 34] are known to differ from that of men; consequently, explanatory factors of the socioeconomic differential in prognosis in CHD might, as well, be different for the two genders.

Therefore, our purpose was two-fold. The first objective was to analyze the association between personal income, a measure of socioeconomic position and recurrent events in women with CHD. The second aim was to determine whether clinical, behavioural and psychosocial factors can explain the social gradient in recurrent events in women with established CHD.

\section{Methods}

Study population

The original study population consisted of 247 women that had either acute myocardial infarction (AMI), or undergone a revascularization procedure either percutaneous coronary intervention (PCI) or coronary artery bypass grafting (CABG) and were hospitalized between 1996 and 2000 at Karolinska University Hospital or St Göran's Hospital in Stockholm, Sweden. The diagnosis of AMI was based on World Health Organization's criteria of typical enzyme patterns and chest pain and/or diagnostic electrocardiographic changes [35]. Consecutively, all eligible women below 75 years were approached and offered to participate in a cardiac rehabilitation program specifically designed for women [36]. Subsequently, all those who agreed to participate were randomly assigned to either the control (128 patients) or to the intervention group (119 patients). Finally, out of the originally randomized 247 patients, 12 (6 from the intervention group, 6 from the control group) did not participate in the study, resulting in 235 eligible patients. Due to missing data on personal income, 188 women were included in the present analyses. Women with complete data did not differ significantly from those with missing data in terms of most of the demographic, lifestyle, psychosocial or clinical characteristics. However, those with missing data were more likely to be from the control group of our intervention program, to have $\mathrm{CABG}$ as inclusion diagnose and to have higher levels of cortisol.

The Ethics Committee of Karolinska Institute at Karolinska University Hospital approved the study.

\section{Measures}

All variables were obtained in the stable phase, approximately 6-8 weeks after hospitalization. 


\section{Income assessment}

Patients were asked to disclose their yearly personal income from the previous year. Six answer possibilities were provided: (1) <119,999, (2) 120,000-159,999, (3) 160,000199,999, (4) 200,000-229,999, (5) 230,000-259,999 and (6) $\geq 260,000$ Swedish crowns (SEK)/year, respectively. In order to optimize the statistical power for the analyses these answer alternatives were categorized into tertiles based on their distribution. Those with income below 119,999 SEK formed the low income group, the medium income group consisted of those in the 120,000-159,999 SEK interval, while those with yearly income above 160,000 SEK were assigned to the high income group.

\section{Ascertainment of biological factors}

Blood samples from the patients were drawn at $10 \pm 1 \mathrm{~h}$ AM. Blood lipids, such as total cholesterol, high- and lowdensity lipoproteins, triglycerides, apolipoprotein A1, apolipoprotein B, lipoprotein (a) were assessed. Cortisol and creatinine levels were measured, as well.

Levels of high-sensitivity C-reactive protein (hsCRP) were measured by nephelometry using $\mathrm{N}$-dilutent for Nephelometry, Behring OUMT 61 (Dade Behring GmbH, Marburg, Germany). Interleukin-6 (IL-6) concentrations were determined by enzyme-linked immunoassay ( $R$ and $D$ Systems, Abingdon, UK). For IL-6, high sensitivity kits were used in order to accurately determine low levels of the cytokine [37].

\section{Assessment of lifestyle-related factors}

Smoking status was categorized as never, current or former smoker. Average daily alcohol intake was calculated in grams. Height and weight were assessed, and body-mass index (BMI) was calculated by dividing the weight with the square of the height value $\left(\mathrm{kg} / \mathrm{m}^{2}\right)$.

\section{Measurement of psychosocial variables}

Psychosocial factors were determined using standardized psychological questionnaires. The 21 items Beck Depression Inventory (BDI) [38] was used to assess depressive symptomatology. Vital exhaustion was measured by means of the Maastricht Questionnaire [39], while the State-Trait Anxiety Inventory [40] was used to determine trait anxiety level. In measuring the availability of social interaction, the shortened version of the Interview Schedule for Social Interaction [41] was used. To determine anger-related characteristics of the participants, the anger symptoms, the anger-in, the anger-out and the anger-discuss subscales of the Framingham Anger Scale [42] were administered.
Hostility scores were extracted from the Jenkins Activity Survey [43].

\section{Other covariates}

Patients were asked to indicate their household's income for the previous year; answer possibilities were identical with those provided to the item concerning personal income. The number of persons relying on the family income was also assessed. Educational attainment was classified into two levels: mandatory schooling only and completion of high school, college or university. Marital status was classified as with or without a partnership. Data on retirement, on drug therapy (beta-blockers, Ca-channel blockers, statins, aspirin and ACE inhibitors) and on whether the patient has been hospitalized due to heart disease in the last few years were collected.

\section{Follow-up}

Patients were followed for all-cause and cardiovascular mortality, and non-fatal AMI over a period of 6 years. The centralized health care system in Sweden provides virtually complete follow-up information for all patients by matching their unique 10 digit person identification numbers to the death and hospital discharge registers. The Swedish hospital discharge registers of AMI were validated using hospital discharge data and mortality data and were found to have adequate sensitivity and specificity [44].

Statistical analyses

Variables that showed skewed distribution were logarithmically transformed for all analyses to approximate normal distribution. However, in Table 1 we present the mean and standard deviation of these data without logarithmic transformation to allow comparison with other studies. One-way ANOVA was used to determine the statistical significance of differences between continuous variables for three groups. Categorical data were compared by chisquare tests.

Un- and multiadjusted Cox proportional hazard models were performed to examine the association between personal income and all-cause death, cardiovascular mortality and the combination of cardiovascular mortality and nonfatal AMI. Due to limited statistical power only age and confounders that were found to modify the regression coefficient associated with low income at least by $10 \%$ [45], i.e. marital status, education, and the interaction term between marital status and age were included in the base model. We also performed several alternative base models when we adjusted-in addition to age, marital status, education, and the interaction term between marital status 
Table 1 Distribution of the study variables according to the level of personal income

\begin{tabular}{|c|c|c|c|c|c|c|}
\hline Variables & $N$ & $\begin{array}{l}\text { Total sample } \\
(n=188)\end{array}$ & $\begin{array}{l}\text { Low personal income } \\
(n=53)\end{array}$ & $\begin{array}{l}\text { Medium personal income } \\
(n=53)\end{array}$ & $\begin{array}{l}\text { High personal income } \\
(n=82)\end{array}$ & $\begin{array}{l}P \\
\text { value }^{\mathrm{a}}\end{array}$ \\
\hline Age (years) & 188 & $62.0(8.9)$ & $64.6(8.8)$ & $64.8(6.4)$ & $58.4(9.0)$ & $<0.001$ \\
\hline Mandatory education only (\%) & 187 & 60.4 & 71.2 & 69.8 & 47.6 & 0.006 \\
\hline Married or cohabiting (\%) & 186 & 57.5 & 67.9 & 48.1 & 56.8 & 0.11 \\
\hline Retired (\%) & 188 & 66.5 & 81.1 & 86.8 & 43.9 & $<0.001$ \\
\hline Inclusion diagnose $^{\mathrm{b}}(\%)$ & 188 & & & & & \\
\hline AMI & & 56.9 & 60.4 & 56.6 & 54.9 & 0.81 \\
\hline CABG & & 30.9 & 30.2 & 22.6 & 36.6 & 0.78 \\
\hline PCI & & 28.2 & 30.2 & 30.2 & 25.6 & 0.22 \\
\hline $\begin{array}{l}\text { Previously hospitalized due to } \\
\text { heart disease }(\%)\end{array}$ & 185 & 96.8 & 98.1 & 96.2 & 96.3 & 0.82 \\
\hline \multicolumn{7}{|l|}{ Drug therapy $(\%)$} \\
\hline ACE inhibitors & 188 & 21.3 & 18.9 & 18.9 & 24.4 & 0.65 \\
\hline Statins & 188 & 56.4 & 52.8 & 60.4 & 56.1 & 0.73 \\
\hline Aspirin & 188 & 88.3 & 92.5 & 83.0 & 89.0 & 0.30 \\
\hline Calcium channel blockers & 188 & 20.2 & 28.3 & 18.9 & 15.9 & 0.20 \\
\hline Beta blockers & 188 & 80.9 & 75.5 & 81.1 & 84.1 & 0.45 \\
\hline $\begin{array}{l}\text { Participated in our subsequent } \\
\text { rehabilitation }(\%)\end{array}$ & 188 & 52.1 & 45.3 & 60.4 & 51.2 & 0.29 \\
\hline $\begin{array}{l}\text { Participated in other rehabilitation } \\
\text { programs }(\%)\end{array}$ & 188 & 22.9 & 15.1 & 22.6 & 28.0 & 0.22 \\
\hline \multicolumn{7}{|l|}{ Lifestyle factors } \\
\hline Smoking & 188 & & & & & 0.96 \\
\hline Never & & 36.2 & 35.8 & 37.7 & 35.4 & \\
\hline Former & & 53.7 & 52.8 & 54.7 & 53.7 & \\
\hline Current & & 10.1 & 11.3 & 7.5 & 11.0 & \\
\hline Alcohol consumption $(\mathrm{g} / \text { days })^{\mathrm{c}}$ & 166 & $2.4(3.5)$ & $2.1(3.1)$ & $1.8(2.4)$ & $2.9(4.2)$ & 0.31 \\
\hline BMI $\left(\mathrm{kg} / \mathrm{m}^{2}\right)$ & 188 & $26.1(4.5)$ & $26.2(4.7)$ & $26.6(5.2)$ & $25.7(3.9)$ & 0.73 \\
\hline \multicolumn{7}{|l|}{ Biological factors } \\
\hline Total cholesterol (mmol/l) & 179 & $5.0(1.1)$ & $5.0(0.9)$ & $5.2(1.1)$ & $4.8(1.1)$ & 0.08 \\
\hline $\mathrm{HDL}(\mathrm{mmol} / \mathrm{l})^{\mathrm{c}}$ & 179 & $1.0(0.3)$ & $1.0(0.3)$ & $1.1(0.4)$ & $1.0(0.4)$ & 0.96 \\
\hline $\mathrm{LDL}(\mathrm{mmol} / \mathrm{l})$ & 179 & $3.1(1.0)$ & $3.1(0.9)$ & $3.3(1.1)$ & $2.9(0.9)$ & 0.90 \\
\hline ApoA1 (g/l) & 180 & $1.5(0.3)$ & $1.6(0.3)$ & $1.5(0.3)$ & $1.4(0.2)$ & 0.05 \\
\hline ApoB (g/l) & 180 & $0.9(0.2)$ & $0.9(0.2)$ & $1.0(0.2)$ & $0.9(0.2)$ & 0.23 \\
\hline Triglycerides $(\mathrm{mmol} / \mathrm{l})^{\mathrm{c}}$ & 179 & $1.8(1.0)$ & $1.8(0.9)$ & $1.8(1.2)$ & $1.8(0.9)$ & 0.95 \\
\hline $\operatorname{LP}(\mathrm{a})(\mathrm{g} / \mathrm{l})^{\mathrm{c}}$ & 180 & $410.3(426.2)$ & $383.0(407.7)$ & $517.2(443.8)$ & $393.7(442.0)$ & 0.04 \\
\hline IL-6 $(\mathrm{mg} / \mathrm{l})^{\mathrm{c}}$ & 179 & $4.5(5.1)$ & $5.9(6.7)$ & $4.2(3.9)$ & $3.7(3.2)$ & 0.08 \\
\hline $\mathrm{hsCRP}(\mathrm{mg} / \mathrm{l})^{\mathrm{c}}$ & 181 & $5.4(9.2)$ & $7.3(11.4)$ & $4.7(7.2)$ & $4.1(6.9)$ & 0.27 \\
\hline Cortisol $(\mathrm{nmol} / \mathrm{l})^{\mathrm{c}}$ & 181 & $284.9(120.1)$ & $283.6(130.2)$ & $284.2(112.4)$ & $268.6(114.9)$ & 0.11 \\
\hline Creatinine $(\mu \mathrm{mol} / \mathrm{l})^{\mathrm{c}}$ & 179 & $71.4(27.8)$ & $72.2(16.0)$ & $75.3(40.5)$ & $69.7(27.7)$ & 0.53 \\
\hline \multicolumn{7}{|l|}{ Psychosocial factors } \\
\hline Depressive symptomatology & 154 & $10.9(6.6)$ & $12.8(6.7)$ & $9.7(6.0)$ & $10.15(6.6)$ & 0.05 \\
\hline Trait anxiety & 175 & $44.6(4.9)$ & $45.2(5.2)$ & $44.5(5.2)$ & $44.1(4.4)$ & 0.44 \\
\hline Vital exhaustion & 159 & $21.1(10.1)$ & $20.9(9.2)$ & $22.0(9.1)$ & $19.8(11.4)$ & 0.54 \\
\hline Availability of social interaction & 162 & $20.7(4.8)$ & $20.6(4.6)$ & $19.0(4.9)$ & $22.2(4.7)$ & 0.002 \\
\hline Hostility & 184 & $7.1(0.9)$ & $7.0(0.9)$ & $7.1(0.9)$ & $7.2(0.9)$ & 0.52 \\
\hline
\end{tabular}


Table 1 continued

\begin{tabular}{lccccc}
\hline Variables & $N$ & $\begin{array}{l}\text { Total sample } \\
(n=188)\end{array}$ & $\begin{array}{l}\text { Low personal income } \\
(n=53)\end{array}$ & $\begin{array}{l}\text { Medium personal income High personal income } \\
(n=53)\end{array}$ & $\begin{array}{l}P \\
(n=82) \\
\text { value }^{\mathrm{a}}\end{array}$ \\
\hline Anger symptoms & 181 & $5.1(3.2)$ & $5.3(3.4)$ & $4.8(3.1)$ & $5.1(3.1)$ \\
Anger-in & 182 & $2.6(1.8)$ & $2.9(1.7)$ & $2.7(1.9)$ & 0.79 \\
Anger-out & 184 & $0.6(0.9)$ & $0.5(0.8)$ & $0.5(0.8)$ & 0.13 \\
Anger-discuss & 182 & $3.0(1.7)$ & $2.6(1.7)$ & $2.8(1.4)$ & $0.6(0.9)$ \\
AMI and cardiovascular death (\%) & 188 & 16.5 & 26.4 & 13.2 & $3.4(1.8)$ \\
Cardiovascular mortality (\%) & 188 & 5.3 & 9.4 & 7.5 & 0.7 \\
Total mortality (\%) & 188 & 9.6 & 20.8 & 7.5 & 0.02 \\
\hline
\end{tabular}

Data are presented as means and standard deviations for continuous variables and as percent for categorical variables. AMI, acute myocardial infarction; CABG, coronary artery bypass grafting; PCI, percutaneous coronary intervention; HDL, high density lipoprotein; LDL, low density lipoprotein; ApoA1, apolipoprotein A1; ApoB, apolipoprotein B; LP (a), lipoprotein (a); hsCRP, high sensitivity C-reactive protein; IL-6, interleukin-6; BMI, body-mass index

${ }^{a} \mathrm{P}$ is the probability value calculated according to one-way ANOVA for continuous data and according to chi-square test for categorical data

b The categories are not mutually exclusive

c The variable was logarithmically transformed because of skewed distribution. Means and standard deviations are presented as values before the logarithmical transformation

and age-for (1) retirement, (2) previous hospitalization in the last years due to CHD, (3) inclusion diagnosis, (4) drug therapy, (5) participation in our subsequent rehabilitation program and (6) participation in other rehabilitation programs. Stratified analyses and formal tests for interactions were conducted, as well, to assess possible effect modification.

In order to examine potential mediators of the association between income and the combination of cardiovascular death and recurrent AMI several lifestyle-related, biological and psychosocial CHD risk factors were added one by one to the base model. We used the change-in-point-estimate strategy [45] to determine to what extent each risk factor contributes to the explanation of the association of interest. The percentage of the contribution of individual risk factors was computed according to the formula:

$\Delta=\frac{\ln \mathrm{HR}_{\text {base model }}-\ln \mathrm{HR}_{\text {base model }+ \text { explanatory factor }}}{\ln \mathrm{HR}_{\text {base model }}} \times 100$

SAS 9.1 and SPSS 11.5 for Windows were used for statistical analyses.

\section{Results}

Baseline characteristics

Table 1 presents the distribution of demographic, lifestyle, clinical and psychosocial factors according to the three levels of the personal income. Women with high personal income were younger than those who earned less. The mean age in the high, medium and low-income groups was 58.4 $(\mathrm{SD}=9.0), 64.8(6.4)$ and $64.6(8.8)$ years, respectively.
Women with higher income tended to be more educated. The percentage of women who had attended only mandatory school was $71.2 \%, 69.8 \%$ and $47.6 \%$ in the low-, medium- and high-income groups, respectively. Women with low and medium income were more likely to have been retired $(81.1 \%$ and $86.8 \%)$ compared to women with high income $(43.9 \%)$. Women with low income were somewhat more likely to live in a partnership $(67.9 \%)$ when compared to women with medium $(48.1 \%)$ or high income $(56.8 \%)$. Inclusion diagnoses, previous hospitalization due to $\mathrm{CHD}$, drug therapy, participation in our rehabilitation program and lifestyle factors were largely comparable across the income groups. Participation in other rehabilitation programs tended to be more frequent as income increased. There was no clear trend concerning the relationship between the different lipids, cortisol and creatinine and income categories. Serum levels of both IL-6 and hsCRP decreased with increasing income.

Women with low personal income had higher BDI scores than women with medium or high income, 12.8 (6.7) versus 9.7 (6.0) and 10.15 (6.6), respectively. The availability of social interaction was the lowest among women with a medium income. Scores on the anger-discuss scale tended to increase with increasing income, while for the anger-in scores an opposite tendency was observed.

Personal income and recurrent events

During the follow-up period there were 18 deaths from any cause $(9.6 \%), 10$ cardiovascular deaths $(5.3 \%)$, while 31 patients had either cardiovascular death or non-fatal AMI $(16.5 \%)$. Income showed an inverse relationship with adverse outcome. Table 2 presents the hazard ratios when 
Table 2 Associations between personal income and prognosis after AMI

\begin{tabular}{|c|c|c|c|c|c|}
\hline \multirow[t]{2}{*}{ Outcome } & \multirow[t]{2}{*}{ Income tertile } & \multirow[t]{2}{*}{$N$} & \multirow[t]{2}{*}{ Number of events } & \multicolumn{2}{|l|}{$\mathrm{HR}$ and $95 \% \mathrm{CI}$} \\
\hline & & & & Unadjusted & Base model $^{\mathrm{a}}$ \\
\hline \multirow[t]{3}{*}{ Cardiovascular mortality and non-fatal AMI } & Low & 53 & 14 & 1 & 1 \\
\hline & Medium & 53 & 7 & $0.47(0.19-1.16)$ & $0.38(0.15-0.97)$ \\
\hline & High & 82 & 10 & $0.46(0.20-1.04)$ & $0.39(0.17-0.93)$ \\
\hline \multirow[t]{3}{*}{ Cardiovascular mortality } & Low & 53 & 5 & 1 & 1 \\
\hline & Medium & 53 & 4 & $0.77(0.20-2.86)$ & $0.57(0.13-2.39)$ \\
\hline & High & 82 & 1 & $0.12(0.02-1.09)$ & $0.12(0.01-1.18)$ \\
\hline \multirow[t]{3}{*}{ All-cause mortality } & Low & 53 & 11 & 1 & 1 \\
\hline & Medium & 53 & 4 & $0.34(0.11-1.08)$ & $0.33(0.10-1.09)$ \\
\hline & High & 82 & 3 & $0.17(0.04-0.63)$ & $0.19(0.05-0.75)$ \\
\hline
\end{tabular}

AMI, acute myocardial infarction; HR, hazard ratio; CI, confidence interval

${ }^{a}$ Base model includes confounders, such as age, marital status, education and the interaction between marital status and age

medium- and high-income groups were compared to the low-income group. When we adjusted for confounders, i.e. age, marital status, education and the interaction between marital status and age, both the medium and high income groups had lower risk for recurrent events than those with low income. Patients in the middle-income group had significantly lower risk for the combination of cardiovascular death and non-fatal AMI than those in the lowincome group, the hazard ratio (HR) and the 95\% confidence interval (CI) being $0.38(0.15-0.97)$. When the groups with high and low income were compared, the multiadjusted models showed significantly higher total mortality and higher risk for the combination of cardiovascular mortality and non-fatal AMI for the latter group. The corresponding HR $(95 \% \mathrm{CI})$ were $0.19(0.05-0.75)$ and 0.39 (0.17-0.93), respectively. When alternatively we categorized income as quartiles we obtained similar results in essence though with less power.

We have also performed alternative base models when we adjusted-in addition to the factors already included to the base model-for (1) retirement, (2) previous hospitalization in the last years due to CHD, (3) inclusion diagnosis, (4) drug therapy (beta blocker, calcium channel blocker, statin, aspirin and ACE inhibitor), (5) participation in our and (6) in other rehabilitation programs. We obtained essentially similar results in these alternative models, i.e. there was no evidence for confounding from these variables.

We have also examined possible effect modifications. We performed stratified analyses according to age (median split), marital status, education, retirement, previous hospitalizations due to CHD, participation in our rehabilitation program, hospital catchment area and inclusion diagnoses. We found roughly similar associations between income and recurrent events in these selected subgroups.
Mediators between income and recurrent events

We have investigated if lifestyle and psychosocial factors, lipids, inflammatory markers, cortisol or creatinine contribute to the explanation of the association between income and recurrent events (Table 3). We found slight decrease in risk associated with the lower income category when adjusting for smoking, depression and anger symptoms. Adjustment for smoking resulted in a decrease of $12.8 \%$ of the risk for the high versus low income group. With depression, the corresponding decrease was $13.5 \%$ when middle and low income groups were compared and 9.3\% when high and low income groups were compared. When adding the anger symptoms scale to the base model the risk of the middle versus low income group was reduced by $16.7 \%$, whereas that corresponding to the high versus low income groups dropped by $10.2 \%$. After controlling for alcohol consumption, anger-in and anger discussion the association between income and the combined endpoint of cardiovascular death and non-fatal AMI became even stronger. The regression coefficient for the high versus low income decreased by $19.4 \%$ after adjustment for alcohol intake and by $14.6 \%$ after controlling for anger discuss. Adjustment for anger-in resulted in a $14.6 \%$ decrease of the regression coefficient for low versus middle income groups. The effect of the additional adjustment for the rest of the potential mediators was negligible.

\section{Additional analyses}

In secondary analyses, we investigated the association between two other measures of SES-educational attainment and household income-and recurrent events. After adjustment for potential confounders, i.e. age, education, marital status and the number of persons relying on the 
Table 3 Hazard ratios and 95\% confidence intervals for the association between income and recurrent events before and after adjustment for potentially mediating factors

\begin{tabular}{|c|c|c|c|}
\hline & $\mathrm{N}$ & Corresponding base model ${ }^{\mathrm{a}} \mathrm{HR}(95 \% \mathrm{CI})$ & $\mathrm{HR}(95 \% \mathrm{CI})$ \\
\hline \multicolumn{4}{|l|}{ Lifestyle factors } \\
\hline \multirow{2}{*}{ Base model + smoking } & \multirow[t]{2}{*}{187} & $0.38(0.15-0.96)$ & $0.40(0.16-1.03)$ \\
\hline & & $0.39(0.16-0.93)$ & $0.44(0.18-1.07)$ \\
\hline \multirow[t]{2}{*}{ Base model + alcohol consumption } & \multirow[t]{2}{*}{166} & $0.46(0.16-1.33)$ & $0.46(0.16-1.34)$ \\
\hline & & $0.55(0.20-1.52)$ & $0.49(0.17-1.38)$ \\
\hline \multirow[t]{2}{*}{ Base model + BMI } & \multirow[t]{2}{*}{187} & $0.38(0.15-0.96)$ & $0.37(0.14-0.93)$ \\
\hline & & $0.39(0.16-0.93)$ & $0.42(0.18-1.01)$ \\
\hline \multicolumn{4}{|l|}{ Biological factors } \\
\hline \multirow[t]{2}{*}{ Base model + total cholesterol } & \multirow[t]{2}{*}{179} & $0.46(0.17-1.19)$ & $0.47(0.18-1.24)$ \\
\hline & & $0.47(0.19-1.16)$ & $0.48(0.19-1.19)$ \\
\hline \multirow{2}{*}{ Base model + HDL cholesterol } & \multirow[t]{2}{*}{179} & $0.46(0.17-1.19)$ & $0.43(0.16-1.14)$ \\
\hline & & $0.47(0.19-1.16)$ & $0.47(0.19-1.16)$ \\
\hline \multirow[t]{2}{*}{ Base model + LDL cholesterol } & \multirow[t]{2}{*}{179} & $0.46(0.17-1.19)$ & $0.48(0.18-1.25)$ \\
\hline & & $0.47(0.19-1.16)$ & $0.48(0.19-1.20)$ \\
\hline \multirow[t]{2}{*}{ Base model + ApoA1 } & \multirow[t]{2}{*}{180} & $0.45(0.17-1.17)$ & $0.45(0.17-1.17)$ \\
\hline & & $0.47(0.19-1.16)$ & $0.47(0.19-1.16)$ \\
\hline \multirow[t]{2}{*}{ Base model + ApoB } & \multirow[t]{2}{*}{180} & $0.45(0.17-1.17)$ & $0.45(0.17-1.17)$ \\
\hline & & $0.47(0.19-1.16)$ & $0.46(0.19-1.16)$ \\
\hline \multirow[t]{2}{*}{ Base model + triglycerides } & \multirow[t]{2}{*}{179} & $0.46(0.17-1.19)$ & $0.45(0.17-1.17)$ \\
\hline & & $0.47(0.19-1.16)$ & $0.48(0.19-1.19)$ \\
\hline \multirow[t]{2}{*}{ Base model + LP (a) } & \multirow[t]{2}{*}{180} & $0.45(0.17-1.17)$ & $0.45(0.17-1.18)$ \\
\hline & & $0.47(0.19-1.16)$ & $0.46(0.18-1.15)$ \\
\hline \multirow[t]{2}{*}{ Base model + IL-6 } & 179 & $0.48(0.18-1.27)$ & $0.46(0.17-1.22)$ \\
\hline & & $0.50(0.20-1.26)$ & $0.49(0.20-1.24)$ \\
\hline Base model + hsCRP & 181 & $0.46(0.17-1.19)$ & $0.45(0.17-1.17)$ \\
\hline & & $0.48(0.19-1.18)$ & $0.47(0.19-1.16)$ \\
\hline Base model + cortisol & 181 & $0.46(0.17-1.19)$ & $0.46(0.18-1.19)$ \\
\hline & & $0.48(0.19-1.18)$ & $0.48(0.19-1.18)$ \\
\hline Base model + creatinine & 179 & $0.46(0.17-1.19)$ & $0.45(0.17-1.18)$ \\
\hline & & $0.47(0.19-1.16)$ & $0.48(0.19-1.17)$ \\
\hline Psychosocial factors & & & \\
\hline Base model + depressive symptomatology & 154 & $0.37(0.11-1.25)$ & $0.42(0.12-1.45)$ \\
\hline & & $0.43(0.15-1.18)$ & $0.47(0.16-1.31)$ \\
\hline Base model + trait anxiety & 174 & $0.45(0.17-1.17)$ & $0.45(0.17-1.17)$ \\
\hline & & $0.44(0.17-1.10)$ & $0.43(0.17-1.10)$ \\
\hline Base model + vital exhaustion & 158 & $0.41(0.14-1.13)$ & $0.41(0.14-1.13)$ \\
\hline & & $0.41(0.16-1.04)$ & $0.41(0.16-1.04)$ \\
\hline Base model + availability of social interaction & 161 & $0.36(0.13-0.99)$ & $0.36(0.13-1.01)$ \\
\hline & & $0.45(0.18-1.13)$ & $0.42(0.16-1.08)$ \\
\hline Base model + hostility & 183 & $0.37(0.15-0.96)$ & $0.37(0.14-0.95)$ \\
\hline & & $0.38(0.16-0.91)$ & $0.38(0.16-0.91)$ \\
\hline Base model + anger symptoms & 181 & $0.48(0.18-1.23)$ & $0.56(0.21-1.48)$ \\
\hline & & $0.49(0.20-1.22)$ & $0.54(0.21-1.35)$ \\
\hline Base model + anger-in & 182 & $0.41(0.16-1.04)$ & $0.36(0.14-0.95)$ \\
\hline & & $0.42(0.17-1.02)$ & $0.45(0.18-1.09)$ \\
\hline Base model + anger-out & 184 & $0.40(0.15-1.02)$ & $0.40(0.16-1.03)$ \\
\hline & & $0.42(0.17-1.01)$ & $0.39(0.16-0.96)$ \\
\hline
\end{tabular}


Table 3 continued

\begin{tabular}{lllr}
\hline & $\mathrm{N}$ & Corresponding base model $^{\mathrm{a}}$ HR $(95 \% \mathrm{CI})$ & $\mathrm{HR}(95 \% \mathrm{CI})$ \\
\hline Base model + anger discussion & 181 & $0.40(0.16-1.03)$ & $0.37(0.14-0.96)$ \\
& & $0.42(0.17-1.02)$ & $0.37(0.15-0.92)$ \\
\hline
\end{tabular}

${ }^{a}$ The base model when patients with missing values for the given potential mediator were excluded. Base model includes age, marital status, education and the interaction between marital status and age. For each variable, the first row represents the hazard ratio for the middle versus the low income group, while the second row represents the risk of the high compared to the low income group

AMI, acute myocardial infarction; CABG, coronary artery bypass grafting; PCI, percutaneous coronary intervention; HDL, high-density lipoprotein; LDL, low-density lipoprotein; ApoA1, apolipoprotein A1; ApoB, apolipoprotein B; LP (a), lipoprotein (a); hsCRP, high sensitivity Creactive protein; IL-6, interleukin-6; BMI, body-mass index

family income, household income was not significantly related to the combined endpoint of cardiovascular mortality and new AMI, the HR (95\% CI) being $0.78(0.32-$ 1.91) for the middle versus the low household income tertile and $0.41(0.12-1.39)$ when comparing groups with high and low household income. Education was not significantly associated with the combined endpoint of cardiovascular mortality and new AMI, the HR (95\% CI) being 0.92 (0.41-2.06) when those having at least high school were compared to those with less than high school education.

\section{Discussion}

This study investigated whether personal income predicts recurrent events in women patients with CHD. In line with previous research $[4,10,12,46]$ we found that low income was associated with higher risk of total and cardiovascular mortality, as well as with an increased risk for the combination of all cause mortality and recurrent AMI.

In explaining socioeconomic inequalities in health two major types of explanations have been suggested [47, 48]. According to the "health selection" or the "reverse causation" hypothesis health determines social position [47, 48]. This health selection can be direct, when unhealthy individuals reduce their social position as a consequence of their inferior health status or indirect, when it operates on the basis of characteristics or background factors that are related to both health and SES [47, 48]. The second set of explanations, known as the "social causation" hypothesis [47] posits that SES affects health and the risk of dying [48].

Health selection as potential explanation of our findings

Although direct health selection, i.e. the outcome measure determining income at baseline was not possible in our study, we can not exclude that previous health condition influenced both income and recurrent events. To address the possibility that those experiencing earlier a cardiac event would be more likely not to be able to work and thereby have a lower income [48], we included previous hospitalizations due to CHD in our multivariate analyses and found no evidence for confounding from this factor.

Similarly, it may be argued that psychosocial factors such as a long history of depression, anxiety, ineffective ways of coping with anger and hostility could eventually cause lower income. However, Lynch and Kaplan [49] and Kristenson and colleagues [50] argue that by differential exposure to environmental challenges, e.g. financial strain, insecure employment, low control over life, stressful life events, low self-esteem [51] and by differences in protective resources, socioeconomic factors are more likely to structure the development and maintenance of social and psychological characteristics than vice versa. For example, in the Whitehall II study the social variation in depression and psychological well-being was largely mediated by factors related to environmental challenges and protective resources, i.e. individual behaviours, psychosocial characteristics at work and social circumstances outside work [47]. Moreover, during the period when our study was conducted the amount of sick allowance in Sweden represented $90 \%$ of the previous salary; therefore a sick leave period due to previous CHD or depression was not likely to cause considerable income reduction.

\section{CHD risk factors as explanatory factors for the social} gradient in recurrent events

Besides upstream determinants of the social gradient in recurrent events, we also investigated whether lifestylerelated, biological and psychosocial factors contribute to the explanation of the relationship between income and recurrent events in women cardiac patients. By adding these risk factors one by one to the base model we analyzed to what extent each of the 23 factors contributed to the explanation of the social gradient in CHD outcome.

Concerning the traditional cardiovascular risk factors, adjustment for smoking reduced by $12.8 \%$ the excess risk of recurrent events of the low versus the high income group. This is in agreement with findings from several studies 
showing smoking to contribute to the explanation of the social gradient in CHD morbidity and mortality [1, 7, 9, 30]. Results from studies regarding socioeconomic differences in smoking have to be interpreted with caution given that smoking is more socially accepted in low socioeconomic strata and therefore individuals from these groups might report their smoking more honestly. Differences in smoking among the income groups may therefore be even smaller than we actually found, thus the mediatory effect of smoking could eventually be overestimated. Adjustment for alcohol consumption resulted in a stronger association between income and recurrent events. The traditional biological risk factors included in our study and BMI contributed only modestly to the differences in recurrent events across the income groups.

Besides the well established CHD risk factors, other, so called non-traditional risk factors-inflammatory markers and psychosocial factors among others-have been suggested to be pathways through which unfavourable social circumstances may lead to $\mathrm{CHD}[8,28,29,52]$ or to poor outcome in established disease [10, 20, 31]. Although others have found evidence for an inverse relationship between socioeconomic status and inflammatory markers $[19,20,53]$ and inflammatory markers and CHD outcome [54], our data did not support a contribution of IL-6 or hsCRP to the explanation of the differences in recurrent events among the income groups.

Adjustment for anger symptoms reduced the excess risk for recurrent events associated with being in the low income group, whereas adjustment for anger-in and anger discussion resulted in stronger income-recurrent events relationship. Anger has been shown to differ among SES groups [16] and to predict prognosis in CHD [55]. We believe our study is the first to examine it as a potential intermediate factor for the social differences in CHD.

Depressive symptomatology also contributed to the explanation of the association between income and recurrent events. The social gradient in depressive symptoms is well documented [56], whereas depression has been consistently shown to predict CHD or poor outcome in already established disease [57]. So far, depression as a link between socioeconomic status and recurrent events in CHD women patients has not yet been investigated. Studies conducted on this topic on male AMI survivors [31] or on initially healthy samples did not show a mediatory effect of depression for the association between SES and CHD-related outcome [5, 58].

Similarly to other studies investigating social support as a link between poor socioeconomic circumstances and recurrent events in CHD [10, 31], we did not find evidence for a mediating effect for this factor. Neither anxiety, nor vital exhaustion, hostility or the three other anger- related behaviours contributed to the explanation of the investigated association.
Differences in treatment as potential explanations for the social gradient in recurrent events

Differences in access to medical care among the income groups in our study are not likely to have contributed to differences in survival as the healthcare system in Sweden is universal. However, studies conducted in both countries with and without universal health care indicate that relative to their needs, cardiac patients with low socioeconomic position are less frequently offered revascularization procedures, adequate drug therapy and rehabilitation programs compared to their better situated counterparts $[46,59,60]$. Nevertheless, we found no differences in inclusion diagnose, medication or participation in cardiac rehabilitation among women with different SES, nor was there evidence that these factors contributed to the explanation of the relationship between income and recurrent events. These results are in agreement with those of a recent Swedish study which found no socioeconomic differences in cardiac revascularization procedures in women patients with CHD [61].

\section{Limitations}

Our study has several limitations which need to be considered when interpreting the results.

First, including only women from the larger Stockholm area who survived at least 6-8 weeks after hospitalization for a cardiac event limits the generalizibility of our findings to only urban dwelling women who are in a stable phase after a cardiac event.

Second, since only women were included in our study, no conclusions regarding male survivors of $\mathrm{CHD}$ can be drawn. However, since women have been underrepresented in cardiovascular research, studies conducted among women cardiac patients have a good potential to add to this area of research.

Third, recruitment in the study could have also resulted in selection bias as patients who are healthier and otherwise more advantaged are more likely to be willing to participate in rehabilitation programs than their worse situated counterparts [62, 63].

Fourth, due to the small number of recurrent events occurring during the follow-up the number of confounders we could adjust for in the base model was limited. However, we performed several alternative base models and found no indication for residual confounding. Similarly, the changes in point estimates after adding the potential mediators to the base model should be regarded as indicative. Comparing estimates before and after adjustment for the potential mediators is the most common method to evaluate intermediary effects. However, it has limitations. The actual percentage change does not quantify the actual mediation, rather just indicates it [64]. To decide whether 
the changes in the point estimates after adjustment for potential mediators reflect causal relations and are not due to chance, our analyses need to be replicated in other samples of women with CHD.

Finally, using income as an indicator of socioeconomic position has the disadvantage of being subject to reverse causation, i.e. health status may affect levels of income. However, as already presented, we found no evidence for confounding from previous hospitalizations due to CHD. Similarly, as personal income and psychological factors were measured at the same point in time it is not possible to determine the causal relationship between these factors. However, Lynch and Kaplan [49] and Kristenson and colleagues [50] argue that by differences in exposure to environmental challenges and in protective resources, socioeconomic factors are more likely to structure the development and maintenance of social and psychological characteristics than the other way round. Despite its drawbacks, income is a useful measure of SES because it relates directly to the material conditions that may influence health [49]; it provides means in purchasing health care, better nutrition, housing, schooling and recreation [65]. It was suggested to be a better indicator of SES in adulthood and old age than education or occupational class because education is more reflective of adolescence and young adulthood SES, while occupational class can be applied only for working individuals [49]. Similarly, it may be argued that the socioeconomic position of the partner or household income may be a better indicator for women's SES than their personal income. However, we believe that in a country like Sweden, where the majority of women and almost the same proportion as men $(80 \%$ of women and $86 \%$ of men) are gainfully employed [66], personal income is a good measure for women's social position. These advantages of the personal income as an indicator of SES may explain eventually why personal and not household income or education were predictive of recurrent events in this sample of women CHD patients.

\section{Conclusions}

In conclusion, our results indicate that low personal income is a risk factor for long term cardiovascular mortality or new AMI in women patients after a cardiac event and that smoking habits, depressive symptomatology and anger symptoms may contribute to the explanation of this relationship.

Acknowledgments The study was supported by grants from the Ansgarius Foundation, the King Gustaf V:s and the Queen Victoria's Foundation, the Swedish Heart and Lung Foundation, the Public Health Committee and the EXPO-95 of Stockholm County Council, the Swedish Medical Research Council (project 19X-11629), and the Vardal Foundation, all in Stockholm, Sweden.

Open Access This article is distributed under the terms of the Creative Commons Attribution Noncommercial License which permits any noncommercial use, distribution, and reproduction in any medium, provided the original author(s) and source are credited.

\section{References}

1. Marmot MG, Bosma H, Hemingway H, Brunner E, Stansfeld S. Contribution of job control and other risk factors to social variations in coronary heart disease incidence. Lancet. 1997;350:235-9. doi:10.1016/S0140-6736(97)04244-X.

2. Picciotto S, Forastiere F, Stafoggia M, D'Ippoliti D, Ancona C, Perucci CA. Associations of area based deprivation status and individual educational attainment with incidence, treatment, and prognosis of first coronary event in Rome, Italy. J Epidemiol Community Health. 2006;60:37-43. doi:10.1136/jech.2005.03 7846.

3. Rosengren A, Wedel H, Wilhelmsen L. Coronary heart disease and mortality in middle aged men from different occupational classes in Sweden. Br Med J. 1988;297:1497-1500.

4. Salomaa V, Niemela M, Miettinen H, Ketonen M, ImmonenRaiha P, Koskinen S, et al. Relationship of socioeconomic status to the incidence and prehospital, 28-day, and 1-year mortality rates of acute coronary events in the FINMONICA myocardial infarction register study. Circulation. 2000;101:1913-18.

5. Thurston RC, Kubzansky LD, Kawachi I, Berkman LF. Do depression and anxiety mediate the link between educational attainment and CHD? Psychosom Med. 2006;68:25-32. doi: 10.1097/01.psy.0000195883.68888.68.

6. Lynch JW, Kaplan GA, Cohen RD, Tuomilehto J, Salonen JT. Do cardiovascular risk factors explain the relation between socioeconomic status, risk of all-cause mortality, cardiovascular mortality, and acute myocardial infarction? Am J Epidemiol. 1996;144:934-42.

7. Pocock SJ, Shaper AG, Cook DG, Phillips AN, Walker M. Social class differences in ischaemic heart disease in British men. Lancet. 1987;2:197-201. doi:10.1016/S0140-6736(87)90774-4.

8. Marmot MG, Shipley MJ, Rose G. Inequalities in death-specific explanations of a general pattern? Lancet. 1984;1:1003-6. doi: 10.1016/S0140-6736(84)92337-7.

9. Strand BH, Tverdal A. Can cardiovascular risk factors and lifestyle explain the educational inequalities in mortality from ischaemic heart disease and from other heart diseases? 26 year follow up of 50,000 Norwegian men and women. J Epidemiol Community Health. 2004;58:705-9. doi:10.1136/jech.2003.01 4563.

10. Alter DA, Chong A, Austin PC, Mustard C, Iron K, Williams JI, et al. Socioeconomic status and mortality after acute myocardial infarction. Ann Intern Med. 2006;144:82-93.

11. Manderbacka K, Hetemaa T, Keskimaki I, Luukkainen P, Koskinen S, Reunanen A. Are there socioeconomic differences in myocardial infarction event rates and fatality among patients with angina pectoris? J Epidemiol Community Health. 2006;60:442-7. doi:10.1136/jech.2005.041566.

12. Rasmussen JN, Rasmussen S, Gislason GH, Buch P, Abildstrom SZ, Kober L, et al. Mortality after acute myocardial infarction according to income and education. J Epidemiol Community Health. 2006;60:351-6. doi:10.1136/jech.200X.040972.

13. Kaplan GA, Keil JE. Socioeconomic factors and cardiovascular disease: a review of the literature. Circulation. 1993;88:1973-8. 
14. Pickering T. Cardiovascular pathways: socioeconomic status and stress effects on hypertension and cardiovascular function. Ann N Y Acad Sci. 1999;896:262-77. doi:10.1111/j.1749-6632.1999.tb 08121.x.

15. Jacobsen BK, Thelle DS. Risk factors for coronary heart disease and level of education The Tromso Heart Study. Am J Epidemiol. 1988;127:923-32.

16. Matthews KA, Kelsey SF, Meilahn EN, Kuller LH, Wing RR. Educational attainment and behavioral and biologic risk factors for coronary heart disease in middle-aged women. Am J Epidemiol. 1989;129:1132-44.

17. Mayer O Jr, Simon J, Heidrich J, Cokkinos DV, De Bacquer D, EUROASPIRE II Study Group. Educational level and risk profile of cardiac patients in the EUROASPIRE II substudy. J Epidemiol Community Health. 2004;58:47-52. doi:10.1136/jech.58.1.47.

18. Engstrom G, Tyden P, Berglund G, Hansen O, Hedblad B, Janzon L. Incidence of myocardial infarction in women. A cohort study of risk factors and modifiers of effect. J Epidemiol Community Health. 2000;54:104-7. doi:10.1136/jech.54.2.104.

19. Jousilahti P, Salomaa V, Rasi V, Vahtera E, Palosuo T. Association of markers of systemic inflammation, $\mathrm{C}$ reactive protein, serum amyloid $\mathrm{A}$, and fibrinogen, with socioeconomic status. J Epidemiol Community Health. 2003;57:730-3. doi:10.1136/jech. 57.9.730.

20. Lubbock LA, Goh A, Ali S, Ritchie J, Whooley MA. Relation of low socioeconomic status to C-reactive protein in patients with coronary heart disease (from the heart and soul study). Am J Cardiol. 2005;96:1506-11. doi:10.1016/j.amjcard.2005.07.059.

21. Wamala SP, Murray MA, Horsten M, Eriksson M, SchenckGustafsson K, Hamsten A, et al. Socioeconomic status and determinants of hemostatic function in healthy women. Arterioscler Thromb Vasc Biol. 1999;19:485-92.

22. Wilson TW, Kaplan GA, Kauhanen J, Cohen RD, Wu M, Salonen $\mathrm{R}$, et al. Association between plasma fibrinogen concentration and five socioeconomic indices in the Kuopio Ischemic Heart Disease Risk Factor Study. Am J Epidemiol. 1993;1:292-300.

23. Colhoun HM, Hemingway H, Poulter NR. Socio-economic status and blood pressure: an overview analysis. J Hum Hypertens. 1998;12:91-110. doi:10.1038/sj.jhh.1000558.

24. Kristenson M, Kucinskiene Z, Bergdahl B, Orth-Gomer K. Risk factors for coronary heart disease in different socioeconomic groups of Lithuania and Sweden-the LiVicordia Study. Scand J Public Health. 2001;29:140-50.

25. Cheok F, Schrader G, Banham D, Marker J, Hordacre AL. Identification, course, and treatment of depression after admission for a cardiac condition: rationale and patient characteristics for the Identifying Depression As a Comorbid Condition (IDACC) project. Am Heart J. 2003;146:978-84. doi:10.1016/S0002-8703 (03)00481-2.

26. Brummett BH, Barefoot JC, Siegler IC, Clapp-Channing NE, Lytle BL, Bosworth HB, et al. Characteristics of socially isolated patients with coronary artery disease who are at elevated risk for mortality. Psychosom Med. 2001;63:267-72.

27. Eaker ED, Sullivan LM, Kelly-Hayes M, D’Agostino RB Sr, Benjamin EJ. Anger and hostility predict the development of atrial fibrillation in men in the Framingham Offspring Study. Circulation. 2004;109:1267-71. doi:10.1161/01.CIR.00001185 35.15205.8F.

28. Rose G, Marmot MG. Social class and coronary heart disease. $\mathrm{Br}$ Heart J. 1981;45:13-19. doi:10.1136/hrt.45.1.13.

29. Suadicani P, Hein HO, Gyntelberg F. Strong mediators of social inequalities in risk of ischaemic heart disease: a six-year followup in the Copenhagen Male Study. Int J Epidemiol. 1997;26:51622. doi:10.1093/ije/26.3.516.

30. Woodward M, Oliphant J, Lowe G, Tunstall-Pedoe H. Contribution of contemporaneous risk factors to social inequality in coronary heart disease and all causes mortality. Prev Med. 2003;36:561-8. doi:10.1016/S0091-7435(03)00010-0.

31. Ickovics JR, Viscoli CM, Horwitz RI. Functional recovery after myocardial infarction in men: the independent effects of social class. Ann Intern Med. 1997;127:518-25.

32. Arber S. Comparing inequalities in women's and men's health: Britain in the 1990s. Soc Sci Med. 1997;44:773-87. doi: 10.1016/S0277-9536(96)00185-2.

33. Marrugat J, Sala J, Masia R, Pavesi M, Sanz G, Valle V, et al. Mortality differences between men and women following first myocardial infarction. JAMA. 1998;280:1405-9. doi:10.1001/ jama.280.16.1405.

34. Vaccarino V, Parsons L, Every NR, Barron HV, Krumholz HM. Sex-based differences in early mortality after myocardial infarction. National Registry of Myocardial Infarction 2 Participants. N Engl J Med. 1999;341:217-25. doi:10.1056/NEJM199 907223410401.

35. Alpert JS, Thygesen K, Antman E, Bassand JP. Myocardial infarction redefined-a consensus document of The Joint European Society of Cardiology/American College of Cardiology Committee for the redefinition of myocardial infarction. J Am Coll Cardiol. 2000;36:959-69. doi:10.1016/S0735-1097(00)00 804-4.

36. Koertge J, Janszky I, Sundin O, Blom M, Georgiades A, Laszlo $\mathrm{KD}$, et al. Effects of a stress management program on vital exhaustion and depression in women with coronary heart disease: a randomized controlled intervention study. J Intern Med. 2008;263:281-93. doi:10.1111/j.1365-2796.2007.01887.x.

37. Janszky I, Lekander M, Blom M, Georgiades A, Ahnve S. Selfrated health and vital exhaustion, but not depression, is related to inflammation in women with coronary heart disease. Brain Behav Immun. 2005;19:555-63. doi:10.1016/j.bbi.2005.01.001.

38. Beck AT, Ward CH, Mendelson M, Mock J, Erbaugh J. An inventory for measuring depression. Arch Gen Psychiatry. 1961;4:561-71.

39. Appels A, Hoppener P, Mulder P. A questionnaire to assess premonitory symptoms of myocardial infarction. Int J Cardiol. 1987;17:15-24. doi:10.1016/0167-5273(87)90029-5.

40. Spielberger CD. Manual for the state-trait anxiety inventory (STAI). PaloAlto, CA: Consulting Psychologists Press; 1983.

41. AL Unden, Ort-Gomer K. Development of a social support instrument for use in population surveys. Soc Sci Med. 1989;19:1398-92.

42. Haynes SG, Levine S, Scotch N, Feinleib M, Kannel WB. The relationship of psychosocial factors to coronary heart disease in the Framingham study. I. Methods and risk factors. Am J Epidemiol. 1978;107:362-83.

43. Jenkins CD, Zyzanski SJ, Rosenman RH. Progress toward validation of a computer-scored test for the type A coronary-prone behavior pattern. Psychosom Med. 1971;33:193-202.

44. Hammar N, Nerbrand C, Ahlmark G, Tibblin G, Tsipogianni A, Johansson $\mathrm{S}$, et al. Identification of cases of myocardial infarction: hospital discharge data and mortality data compared to myocardial infarction community registers. Int $\mathrm{J}$ Epidemiol. 1991;20:114-20. doi:10.1093/ije/20.1.114.

45. Rothman KJ, Greenland S. Modern epidemiology. Philadelphia: Lippincott-Raven; 1998.

46. Rao SV, Schulman KA, Curtis LH, Gersh BJ, Jollis JG. Socioeconomic status and outcome following acute myocardial infarction in elderly patients. Arch Intern Med. 2004;164:112833. doi:10.1001/archinte.164.10.1128.

47. Marmot M, Ryff CD, Bumpass LL, Shipley M, Marks NF. Social inequalities in health: next questions and converging evidence. Soc Sci Med. 1997;44:901-10. doi:10.1016/S0277-9536(96)00194-3.

48. Goldman N. Social inequalities in health. Disentangling the underlying mechanisms. Ann N Y Acad Sci. 2001;954:118-39. 
49. Lynch J, Kaplan G. Socioeconomic position. In: Berkman L, Kawachi I, editors. Social epidemiology. New York: Oxford University Press; 2000. p. 13-35.

50. Kristenson M, Eriksen HR, Sluiter JK, Starke D, Ursin H. Psychobiological mechanism of socioeconomic differences in health. Soc Sci Med. 2004;58:1511-22. doi:10.1016/S0277-9536(03)003 53-8.

51. Brunner E. Stress and the biology of inequality. Br Med J. 1997;314:1472-6.

52. Bucher HC, Ragland DR. Socioeconomic indicators and mortality from coronary heart disease and cancer: a 22-year followup of middle-aged men. Am J Public Health. 1995;85:1231-6.

53. Gemes K, Ahnve S, Janszky I. Inflammation a possible link between economical stress and coronary heart disease. Eur J Epidemiol. 2008;23:95-103. doi:10.1007/s10654-007-9201-7.

54. Danesh J, Collins R, Appleby P, Peto R. Association of fibrinogen, C-reactive protein, albumin, or leukocyte count with coronary heart disease: meta-analyses of prospective studies. JAMA. 1998;279:1477-82. doi:10.1001/jama.279.18.1477.

55. Mendes de Leon CF, Kop WJ, de Swart HB, Bar FW, Appels AP. Psychosocial characteristics and recurrent events after percutaneous transluminal coronary angioplasty. Am J Cardiol. 1996;77:252-5. doi:10.1016/S0002-9149(97)89388-5.

56. Gallo LC, Matthews KA. Do negative emotions mediate the association between socioeconomic status and health? Ann N Y Acad Sci. 1999;896:226-45. doi:10.1111/j.1749-6632.1999. tb08118.x.

57. Hemingway H, Marmot M. Evidence based cardiology: psychosocial factors in the aetiology and prognosis of coronary heart disease. Systematic review of prospective cohort studies. Br Med J. 1999;318:1460-7.
58. Gallo LC, Matthews KA, Kuller LH, Sutton-Tyrrell K, Edmundowicz D. Educational attainment and coronary and aortic calcification in postmenopausal women. Psychosom Med. 2001;63:925-35.

59. Rathore SS, Berger AK, Weinfurt KP, Feinleib M, Oetgen WJ, Gersh BJ, et al. Race, sex, poverty, and the medical treatment of acute myocardial infarction in the elderly. Circulation. 2000;102:642-8.

60. Alter DA, Iron K, Austin PC, Naylor CD, SESAMI Study Group. Socioeconomic status, service patterns, and perceptions of care among survivors of acute myocardial infarction in Canada. JAMA. 2004;291:1100-7. doi:10.1001/jama.291.9.1100.

61. Haglund B, Köster M, Nilsson T, Rosén M. Inequality in access to coronary revascularization in Sweden. Scand Cardiovasc J. 2004;38:334-9. doi:10.1080/14017430410021516.

62. Sorensen HT, Lash TL, Rothman KJ. Beyond randomized controlled trials: a critical comparison of trials with nonrandomized studies. Hepatology. 2006;44:1075-82. doi:10.1002/hep.21404.

63. McKee M, Britton A, Black N, McPherson K, Sanderson C, Bain C. Methods in health services research. Interpreting the evidence: choosing between randomised and non-randomised studies. $\mathrm{Br}$ Med J. 1999;319:312-15.

64. Robins JM, Greenland S. Identifiability and exchangeability for direct and indirect effects. Epidemiology. 1992;3:143-55. doi: 10.1097/00001648-199203000-00013.

65. Adler NE, Newman K. Socioeconomic disparities in health: pathways and policies. Health Aff. 2002;21:60-76. doi:10.1377/ hlthaff.21.2.60.

66. Statistics Sweden. Women and men is Sweden. Facts and figures 2006. Stockholm: Statistics Sweden; 2006. 